EDITORIAL

\title{
Educational governance for the regulation of industry sponsored continuing medical education in interventional and device based therapies
}

\author{
J M Morgan, J Marco, L Stockx, F Zannad
}

Heart 2005;91:710-712. doi: 10.1136/hrt.2004.046839

The relationship between industry and clinicians in educational programmes needs to be regulated. Industry may be best placed to deliver educational programmes in "craff" related specialties and particularly in areas where device implantation/technology based therapy has a major clinical role. The authors supervise industry sponsored clinical teaching at a purpose built independent teaching facility, and have developed the concept of educational governance to regulate their relationship with their industry sponsor and that concept is presented.

See end of article for authors' affiliations

Correspondence to: Dr John M Morgan Wessex Cardiothoracic Centre, Southampton University Hospitals, Southampton SO16 6YD, UK; jmm@cardiology. co.uk
$\mathrm{T}$ he educational and research relationships between physicians, allied healthcare professionals, and industry must be regulated. In this way, concern that commercial influence compromises the integrity of clinical teachers in continuing medical education programmes or that financial motivation drives uptake of pharmacological or device based therapies will be alleviated. Also, the skill base in technology based therapies that exists in commercial organisations can be embraced by professional organisations, universities, and other stakeholders that contribute to delivery of clinical care.

There is a reservoir of theoretical and clinical expertise, and financial resources, within industry that make clinical research and educational activity possible. This potential needs to be exploited for the common good. However, there is a tension between the need to exploit the potential of commercial organisations for research and education and the need to protect clinicians and professional institutions from criticism if it is perceived that clinical practice is becoming commercially driven. Various national regulatory mechanisms exist for research and educational activities but have been developed with more emphasis on the pharmaceutical industry ${ }^{1-5}$ than technology based therapies. ${ }^{6}$ Also, the ethical issues related to industry the solicitation of support for therapies by inducements to medical practitioners regulated. ${ }^{7}$ This approach is not orientated towards interventional and device based therapies where there are some important and distinct issues. In high technology medicine, and particularly in the practise of interventional and device based therapies, the complexity of therapy delivery sponsored education have been considered and makes for educational needs that can only be met by close physician-industry relationships. Overall, the mechanisms of regulating commercial-physician relationships in research and continuing medical education, that have been developed in relation to pharmacotherapy, are not simply translatable to interventional and device based therapies.

We present a code of conduct that regulates our relationship with industry as clinical teachers taking advantage of industry sponsored facilities in the field of interventional and device therapies.

\section{RESEARCH GOVERNANCE}

The ethical realities of drug funding sponsorship have been recognised and reviewed by the US Food and Drug Administration. ${ }^{4}{ }^{8}$ The scientific contribution of industry funded research is well recognised. Care is taken to avoid compromising relationships with patients and the integrity of the research. Medical practitioners and the pharmaceutical industry serve interests that may overlap or conflict and there is strong evidence that doctors' clinical and research views and practices are influenced by industry. ${ }^{13} 79$ Openness and transparency of conduct of doctors are the watchwords. Defined procedures should govern research sponsorships. ${ }^{10}$ In industry sponsored studies (for example, AVID (antiarrhythmics versus implantable defibrillators) ${ }^{11}$ and MADIT (multicenter automatic defibrillator implantation trial) ${ }^{12}{ }^{13}$ studies) concern has been expressed about the influence of industry on study design. While there is no such thing as "a free lunch", ${ }^{14}$ physicians leading technology based medical research maintain the highest standards of integrity and independence. It is unrealistic to suggest that studies to reconfirm the evidence base provided by industry sponsored studies are either financially or ethically possible. In the UK the conduct of clinical research has been codified by the development of the concept of research governance ${ }^{15}$ and this type of regulatory assessment needs to be a cornerstone of all future studies, industry sponsored or otherwise. We have developed a code of conduct to apply to continuing medical education in a similar manner.

\section{CONTINUING MEDICAL EDUCATION IN TECHNOLOGY BASED MEDICINE}

Continuing medical education has assumed great importance over the past decade. The pace of change in clinical practice has accelerated 
throughout medicine, in all specialties and subspecialties and among a range of healthcare workers as well as doctors. There is a debate in Europe and the USA as to the necessity of and mechanisms for regulation of industry sponsored medical education, but there are significant differences in emphasis. ${ }^{16}$ The problems posed by financial inducement and bias in interpretation and implementation of the evidence base have been recognised and mechanisms are developed to protect healthcare delivery from this. ${ }^{701417}$ It is arguable that special circumstances require particular regulatory approaches in medical fields relying on highly technical therapies. For example, orthopaedic surgeons in the USA have developed specific guidelines codifying educational practices in their field. ${ }^{10}$ High technology and device based therapies have assumed increasing importance in cardiology and vascular medicine in the past two decades. The population of patients requiring such therapies now far exceeds that simply requiring cardiac pacing which hitherto was the principle example of complex technology employed in cardiology and vascular medicine. The range of skills required for clinical application of these new technology based therapies has also greatly increased and puts significant educational burden on physicians and the educational programmes offered by professional associations and governing bodies of medical practice. Commercial organisations, which have developed these therapies, have taken the lead in providing the educational framework to see deployment of these therapies. It clearly is a commercial necessity for physicians to be trained in high technology therapies for these organisations to see clinical use of their products and the development of industry based education programmes is not simply altruistic. However, commercially driven training programmes do have genuine and significant benefit for patients by enhancement of physician and allied professional skills.

The high technology nature of interventional cardiology/ vascular and device based therapy requires industry sponsored education with sophisticated training programmes for optimal implementation. Their innovative nature and pace of change puts continuing medical education of the necessary quality and sophistication beyond the resources of conventional teaching institutions, including universities. Even national and European professional associations do not have the necessary technical infrastructure or expertise. In short, continuing medical education in high technology medicine, particularly in the cardiovascular field, relies on industry sponsorship for its proper delivery to healthcare professionals. Without this sponsorship complex new therapies would be introduced into clinical practice with great difficulty. It is a part of industry's corporate responsibility to meet this educational need.

\section{CONTINUING MEDICAL EDUCATION IN THE EUROPEAN UNION}

The European Union of Medical Specialists expressed the importance of continuing medical education in its Dublin declaration. ${ }^{18}$ In particular it was stated that doctors' salaries should provide sufficient funds for study leave and the expense associated with professional training. This latter suggestion is increasingly unrealistic. The demand and need for education is increasing. There is no specified period of time that should be spent in ongoing education. However, budget for and duration of annual study leave is wholly inadequate in some European states to satisfy the educational needs of high technology medical fields. While encouraging and even mandating continuing medical education, national institutions and funders of healthcare have failed to properly provide for it. Against this backdrop, criticism of industry sponsored medical education is unnecessarily obstructive and hypocritical.

\section{EDUCATIONAL GOVERNANCE IN THE DEVICE INDUSTRY}

The authors supervise clinical teaching at an industry sponsored but educationally independent facility. The industry partner has provided logistical and technical support to field leaders and their host institutions to achieve a programme of clinical education that receives European Board Accreditation for much of its content. ${ }^{19}$ This testifies to the programme's academic independence and non-proprietary approach to interventional and device based technologies and is a good example of industry cooperating with clinical science in a credible educational endeavour. In addition, the use of sophisticated teaching approaches, including virtual reality and remote learning facilities, maximises educational value. Given the technical and practical skills that need to be acquired for delivery of complex interventional and device based therapies, such a programme would be unattainable without the cooperation of industry. However, the programme leaders have set out standards for the governance of their educational programme. This has enabled them to take advantage of this industry sponsored facility while ensuring the integrity and impartiality of teaching content.

It is suggested that this code of conduct, termed educational governance, could act as a basis for future debate on the regulation of the relationship between commercial organisations and physicians participating in continuing medical education in the rapidly evolving arenas of interventional cardiology, vascular medicine, and device based clinical medicine. There is a need for the partnership in education and clinical training that exists between physicians and commercial organisations to flourish and maintain its educational and scientific purity. Educational governance may help in that endeavour. Whether the healthcare industry provides the infrastructure for an educational programme, unrestricted educational grants or partners with other organisations (university, Royal College, national society), it can contribute to the creation of a "virtual school of technology based medicine" and partner transparently with physicians and the established educational frameworks and institutions in enhancing continuing medical education for the benefit of patients.

\section{EDUCATIONAL GOVERNANCE}

To satisfy educational governance, an educational programme will be:

- "state of the art" and scientifically accurate

- evidence based

- comprehensive

- subject to peer review

- in receipt of CME accreditation (national or international accreditation for continuing medical education)

- non-promotional in content

- led by independent clinicians with complete editorial freedom and who accept clinical responsibility for course content

- subject to attendee feedback and evaluation

- adequately resourced.

To satisfy educational governance, the faculty:

- will be selected according to reputation and clinical skills

- will disclose potential conflicts of interest

- will be transparent about their relationship with industry

- will be committed to teaching of a high standard. 
To satisfy educational governance, suitably qualified participants will:

- have unrestricted access to a chosen course.

\section{CONCLUSION}

Healthcare companies involved in highly technical interventional and device based therapies have specific responsibilities for the support of continuing medical education. A transparent commitment to continuing medical education of healthcare professionals in industry facilitated programmes should be welcomed and encouraged. Formalisation of the educational relationship between physicians and industry should allow a proper balance to be achieved.

\section{ACKNOWLEDGEMENTS}

The authors wish to thank Dr J Ortoli of the European Board of Accreditation and $\mathrm{Mr} \mathrm{H}$ Lambert and Mr J Heemels of Guidant's Institute for Therapy Advancement for their advice and assistance.

\section{Authors' affiliations}

J M Morgan, Wessex Cardiothoracic Centre, Southampton University Hospitals, UK

J Marco, Unite de Cardiologie Interventional Department, Toulouse, France

L Stockx, Ziekenhuis Oost-Limburg Campus, Sint-Jon, Genk, Belgium F Zannad, Department of Cardiovascular Medicine, Hypertension, Heart Failure and Preventive Cardiology Unit and Centre d'Investigation Cliniques CIC INSERM-CHU, Université Henri Poincaré, Nancy, France

\section{REFERENCES}

1 Komesaroff PA, Kerridge $\mathrm{IH}$. Ethical issues concerning the relationships between medical practitioners and the pharmaceutical industry. Med J Australia 2002;176:118-21.
2 Boyce KJ, Parochka J, Overstreet K. Industry sponsorship of continuing medical education. JAMA 2003;290:1149.

3 Frewer A. Sponsorship, conflict of interest and corruption: promoting science in discussion of medical ethics. Wien Med Wochenschr 2002;152(910):234-7.

4 Skolnick A. FDA issues draft 'concept paper' on drug company funding of CME. JAMA 1991;266:2947-8.

5 Rosner F. Pharmaceutical industry support for continuing medical education programs: a review of current ethical guidelines. Mt Sinai J Med 1995;62:427-30

6 Monbiot G. Guard dogs of perception: the corporate takeover of science. Sci Eng Ethics 2003;9:49-57.

7 Brett AS, Burr W, Moloo J. Are gifts from pharmaceutical companies ethically problematic? A survey of physicians. Arch Intern Med 2003;163:2213-8.

8 Rothman KJ. The ethics of research sponsorship. J Clin Epidemiol 1991;44(suppl 1):25S-28S.

9 LSMS Committee on Medical Education. Survey of hospitals and healthcare provider organizations - requirements for physician continuing medical education credits in Louisiana. J La State Med Soc 1999;151:151-3.

10 DelSignore JL. Current guidelines regarding industry-sponsored continuing medical education. Clin Orthop 2003;(412):21-7.

11 Domanski MJ, Sakseena S, Epstein AE, et al. Relative effectiveness of the implantable cardioverter-defibrillator and antiarrhythmic drugs in patients with varying degrees of left ventricular dysfunction who have survived malignant ventricular arrhythmias. AVID Investigators. Antiarrhythmics versus implantable defibrillators. J Am Coll Cardiol 1999:34:1090-5.

12 Moss AJ, Hall WJ, Cannom DS, et al. Improved survival with an implanted defibrillator in patients with coronary disease at high risk for ventricular arrhythmia. N Engl J Med 1996;335:1933-40.

13 Moss AJ, Zareba W, Hall WJ, et al. Prophylactic implantation of a defibrillator in patients with myocardial infarction and reduced ejection fraction. N Engl J Med 2002;346:877-83.

14 Bryan J. Sponsorship. No such thing as a free lunch? Health Serv J 1995; 105:22-5.

15 Sullivan R. United Kingdom research governance strategy: reforming clinical research and development in England. BMJ 2004;328:49-50.

16 Wentz DK. Lessons from comparing CME accreditation in Europe and the United States. Eur J Cancer 2003;39:2422-3.

17 Davis D, Parboosingh J. "Academic" CME and the social contract. Acad Med 1993;68:329-32.

18 European Union of Medical Specialists. Dublin Declaration. Update 1993, Funchal meeting, CP 93/026.

19 Michels HR. Continuing Medical Education in Europe: NVVC, CVOI, ESC, UEMS, and EBAC. Netherlands Heart Journal 2001;9:1-5.

\section{ELECTRONIC PAGES}

\section{Heart Online case reports: www.heartjnl.com}

T

he following electronic only articles are published in conjunction with this issue of Heart.

\section{Very late thrombosis after implantation of sirolimus eluting stent}

E Karvouni, S Korovesis, D G Katritsis

Stent thrombosis after sirolimus eluting stent implantation has been reported to occur at six hours to 375 days after the procedure and usually within the two weeks after discontinuation of antiplatelet medication. A case is reported of very late stent thrombosis after 17 months of sirolimus eluting stent implantation and eight months after clopidogrel discontinuation despite aspirin continuation. This case underlines the possible need for long term antiplatelet medication among patients receiving sirolimus eluting stents.

(Heart 2005;91:e45) www.heartjnl.com/cgi/content/full/91/ $6 / \mathrm{e} 45$

\section{Managing a complication after direct stenting: removal of a maldeployed stent with rotational atherectomy}

M Herzum, R Cosmeleata, B Maisch

A 40 year old patient presented with acute anterior wall infarction. A non-calcified lesion was stented directly without significant expansion of the stent. Rotational atherectomy successfully removed parts of the maldeployed stent and resistant arterial wall substance allowing full dilatation of the lesion.

(Heart 2005;91:e46) www.heartjnl.com/cgi/content/full/91/ $6 / \mathrm{e} 46$

\section{Molecular technique identifies the pathogen} responsible for culture negative infective endocarditis G Y Shin, R J Manuel, S Ghori, S Brecker, A S Breathnach A case of culture negative endocarditis complicated by immune complex glomerulonephritis and severe aortic regurgitation necessitated aortic valve replacement. Empirical treatment with penicillin and gentamicin according to UK guidelines was started. The pathogen, Streptococcus sanguis, was later identified by polymerase chain reaction amplification and sequencing of bacterial $16 \mathrm{~S}$ ribosomal RNA. This molecular technique is likely to be of increasing importance in determining the aetiology of culture negative infective endocarditis, thus providing essential treatment and epidemiological information

(Heart 2005;91:e47) www.heartjnl.com/cgi/content/full/91/ 6/e47 